his ever-increasing scientific and other knowledge. Nor does it help to be told that 'science will find a way', when science has for long been offering solutions, the means of attaining which are not followed by the world at large.

To try in a modest but continuing way to help in the necessary remedying of this last quite deplorable situation of widespread failure to apply available knowledge to alleviate environmental ills, we are founding and convening an open-ended series of Environmental Monographs and Symposia for a leading international publisher, concerning which it is hoped to make a detailed annoucement in our next issue. Their object will be to synthesize and distil, through leading specialists, the knowledge available - including the results of the latest research - in particular subjects or narrower topics, for the widest possible dissemination and practical use. At the same time, with the everchanging situations to be found wherever life is concerned, research must go on, and this we shall continue to encourage through publication of research papers in our Journal-using the device introduced last year, in its sixth volume, of adding to an issue either four or eight pages where necessary to take care of more or longer papers.

The other set of actions which we feel constrained forthwith to advocate for this new year and decade, but in the present instance continuing through and far beyond the latter, is towards saving the world's forests-particularly those that remain in the tropics and subtropics. Tropical rain-forests constitute the richest biome in the world, and many of their component ecosystems teem with more different species of plants, microbiota, and animals-particularly insects- than any other on Earth, although they may be rivalled in this respect by some coral-reefs. But even though it does not help to exaggerate, as has been done, that their 'destruction' would be 'a greater threat to human life than a nuclear war' - unless, of course, it was a narrowly limited one if such were possible - there are also very strong climatic and other reasons for preserving all the areas of tropical rain-forest that can be conserved or turned into tracts of sustained agri-silvicultural productivity.

Consequently we are devoting an unusually large proportion of our Spring issue of this year to the urgent topic of preserving tropical rain-forests - starting the issue (after this Editorial and our following Proposal) with three possibly practicable suggestions from two noted authors, and continuing with examples from South America (between those two authors) and Africa. Further items are under consideration from other parts of Africa and from southeastern Asia for our Summer issue, so we may find ourselves helping to launch a campaign in this vital cause.

N.P.

\title{
PROPOSAL
}

\section{International Year of The Biosphere*}

The time is ripe to step up and expand current efforts to understand the great interlocking systems of air, water, and minerals, that nourish the Earth', wrote Gilbert F. White (President of the International Council of Scientific Unions' Scientific Committee on Problems of the Environment) and Mostafa K. Tolba (Executive Director of the United Nations Environment Programme) in Environmental Conservation (Vol. 6, No. 2, p. 88, 1979).

If, ten years after the United Nations Conference on the Human Environment, which was held in Stockholm in 1972, there still persists no greater public understanding of the biosphere than goldfish have of their aquaria, all other efforts to achieve harmony among ourselves and with our environments may fail.

The onus for action in developing this muchneeded understanding lies, unmistakably, with the United Nations - particularly, we would think, through their Environment Programme.

It is unfortunate, but true, that the vast majority of people now living in the biosphere do not understand what it is, or realize how utterly dependent they are on it for their life-support and very existence.

*Biosphere: The outer 'envelope' of the Earth (including its atmosphere) in which life exists; the total ecological system of our planet Earth.
As a practical step towards creating the necessary public understanding, strengthening measures for the welfare of mankind, and developing initiatives for safeguarding the biosphere, we urge that 1982 be designated by the United Nations and other International Organizations as:

The International Year of The Biosphere.

John R. Vallentyne
Canada Centre for Inland Waters
P.O. Box 5050
Burlington
Ontario L $7 R 4 A 6$
Canada,

J. R. Strickler Australian Institute of Marine Science P.M.B. No. 3, M.S.O.

Townsville

Queensland 4810

Australia,

\&

Nicholas Polunin

Environmental Conservation

15 Chemin F. Lehmann

1218 Grand-Saconnex

Geneva

Switzerland. 